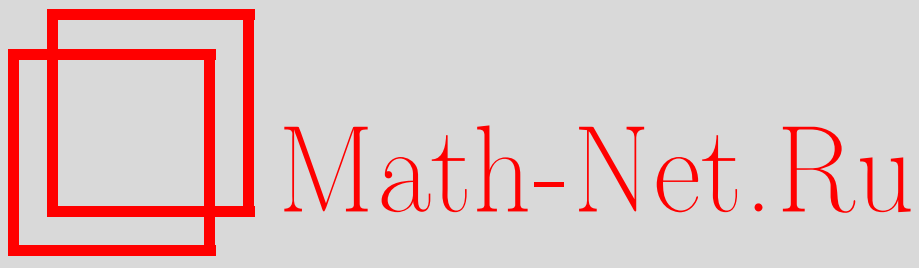

Д. М. Гуреев, С. В. Ямщиков, Разработка технологий АЭ-контроля и их практическая реализация, Вестн. Сам. гос. техн. ун-та. Сер. Физ.-мат. науки, 2005, выпуск $38,82-84$

DOI: https://doi.org/10.14498/vsgtu376

Использование Общероссийского математического портала Math-Net.Ru подразумевает, что вы прочитали и согласны с пользовательским соглашением

http://www . mathnet.ru/rus/agreement

Параметры загрузки:

IP : 52.6 .47 .48

26 апреля 2023 г., 16:01:36

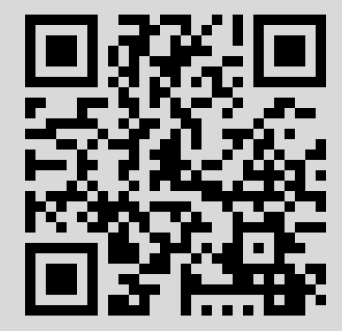




\title{
РАЗРАБОТКА ТЕХНОЛОГИЙ АЭ-КОНТРОЛЯ И ИХ ПРАКТИЧЕСКАЯ РЕАЛИЗАЦИЯ
}

\author{
Разработаны технологии акустико-эмиссионного (АЭ) контроля прочесса вытяжки насосных \\ штанг, восстановления труб демонтированных трубопроводов, сварки труб и последующей экс- \\ плуатации трубопроводов, а также аппаратные и программные средства практической реали- \\ зациии данных технологий.
}

Введение. При разработке ряда технологических процессов и их последующем освоении важное место отводится использованию активных методов неразрушающего контроля, обеспечивающих корректировку параметров этих процессов и отбраковку изделий. К числу таких методов неразрушающего контроля, в первую очередь, относится АЭ-метод, основанный на регистрации и анализе акустических волн, возникающих в материалах при развитии в них процессов структурной перестройки и разрушения [1-4].

В настоящей работе приведены результаты разработки и практической реализации АЭконтроля технологических процессов правки вытяжкой насосных штанг, гидроиспытания восстанавливаемых труб демонтированных трубопроводов, индукционной сварки плетей труб, а также использования АЭ-метода для решения наиболее актуальной задачи контроля состояния труднодоступных подводных участков трубопроводов в процессе их эксплуатации.

Реализация АЭ-контроля. Технологический цикл процесса правки насосных штанг с исходной длиной преимущественно 8,5 м, диаметром 19 мм, изготовленных из стали 20Н2М, включал в себя: закрепление торцов насосной штанги в машине растяжения, вытяжку штанги в течение 2 минут при усилии до $4 \cdot 10^{6} H / \mathrm{M}^{2}$ и выдержку ее в растянутом положении в течение 3 минут. АЭ-контроль процесса правки насосных штанг осуществлялся на стадии выдержки. Использовался двухканальный вариант АЭ-системы, поскольку в данном случае важным представлялось выявление месторасположения критических дефектов, возникающих и развивающихся в процессе пластического деформирования насосных штанг. АЭ-преобразователи стационарно устанавливались на узлах крепления торцов насосной штанги машины растяжения. Регистрировались АЭ-события, их энергетика и координаты АЭ-активных областей.

В результате предварительных экспериментальных исследований с использованием эффекта Кайзера эмпирически определен порог числа регистрируемых АЭ-событий в заданном интервале изменения энергетического параметра, превышение которого служит предпосылкой к отбраковке штанг.

Технология контроля восстанавливаемых труб демонтированных трубопроводов основана на проведении предварительного неразрушающего контроля, включающего в себя визуальный и измерительный контроль труб, ультразвуковую толщинометрию их стенок и измерение твердости металла, дефектоскопию, и последующих гидроиспытаний с одновременным АЭконтролем за состоянием металла труб и сварных швов с целью оперативного выявления скрытых развивающихся дефектов. Процесс контроля и отбраковки труб осуществляется после правки труб, чистки их наружных и внугренних поверхностей и рассортировки труб по наружному диаметру, толщине стенки и длине. На каждом этапе предварительного неразрушающего контроля при выявлении недопустимых дефектов трубы отбраковываются и выводятся из дальнейшего технологического процесса контроля. Завершающий этап контроля и отбраковки труб осуществляется в соответствии с техническими требованиями ГОСТ 10705-80, ГОСТ 8731-87 по группе Д - с нормированием испытательного гидравлического давления при 100\% контроле по ГОСТ 3845-75. Сопутствующий гидроиспытаниям АЭ-контроль как и в случае процесса правки насосных штанг основан на регистрации и анализе АЭ-сигналов (их числа и энергетики) с целью выявления АЭ-активных областей [5], для чего используется двухканальная АЭ-система и линейная схема регистрации с расположением АЭ-преобразователей вблизи торцов труб.

В соответствии с разработанной технологией к эксплуатации допускаются трубы, выдержавшие гидроиспытания и по результатам АЭ-контроля не имеющие скрытых развивающихся дефектов.

Акустико-эмиссионный контроль процесса сварки с формированием кольцевых швов реализован при индукционной сварке плетей труб длиной 10 м, диаметром преимущественно 219 мм и толщиной стенки 11 мм, изготовленных из стали 20. Технологический цикл процесса ин- 
дукционной сварки включал в себя: нанесение на торцевые шлифованные поверхности свариваемых труб слоя раскислителя, приведение этих поверхностей в плотное соприкосновение внутри индуктора, нагрев зоны сварки в течение $50 \ldots 60$ сек до температуры $1150 \ldots 1180{ }^{\circ} \mathrm{C}$, дополнительное поджатие труб друг к другу при сжимающем давлении порядка $7 \cdot 10^{6} \mathrm{H} / \mathrm{m}^{2}$, отключение электронагрева и остывание зоны сварки. АЭ-контроль осуществлялся на стадии остывания сварного шва. Временной интервал АЭ-контроля определялся временем охлаждения сварного шва до температуры $40 \ldots 60$ '․ Регистрировались временные распределения АЭ-событий и энергетического параметра. Задача стояла не в определении местоположения возможных дефектов в сварных швах, а в выявлении и отбраковке в целом швов, характеризующихся интенсивным дефектообразованием при их формировании. Поэтому использовался одноканальный вариант АЭ-системы. АЭ-преобразователь прикреплялся к поверхности одной из свариваемых труб с помощью магнитного держателя на расстоянии около 1 м от места стыка (сварки) труб после приведения их в соприкосновение и до начала процӨсспоннпреерезультат разработки АЭ-контроля процесса индукционной сварки плетей труб сводится к выявлению условного критерия отбраковки дефектных сварных швов из анализа временных зависимостей числа АЭ-событий и энергетического параметра (рис. 1 и 2). Динамика АЭ-параметров прослеживалась, исходя из условий теплоотвода, задаваемых теплофизическими характеристиками стали, геометрическими размерами свариваемых труб, конвективным теплообменом зоны сварного шва с окружающей средой [6], и достижения в процессе охлаждения сварного шва температур развития структурно-фазовых превращений и перехода стали из области пластической деформации в область упругой деформации [7].

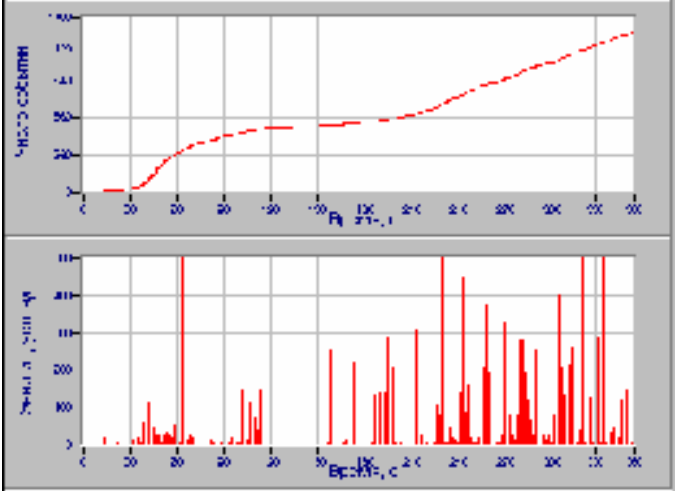

Р и с. 1. Результат АЭ-контроля для качественного сварного шва

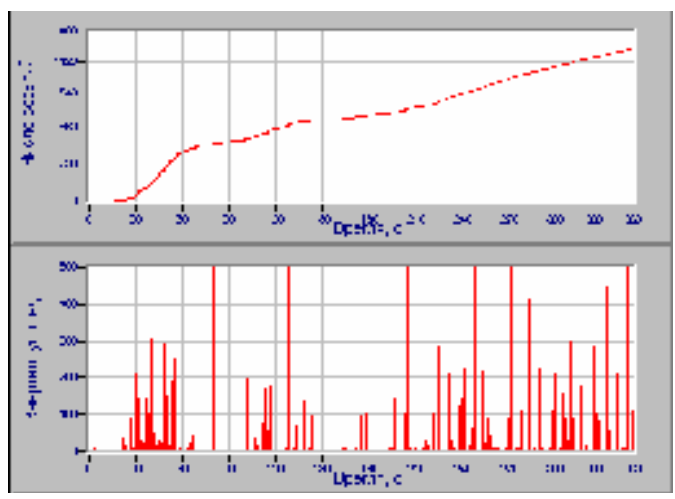

Р и с. 2. Результат АЭ-контроля для дефектного сварного шва

Выявление условного критерия отбраковки дефектных сварных швов осуществлялось на основе сопоставительного анализа результатов АЭ-контроля с данными механических испытаний произвольно выбранных сформированных сварных швов на статический изгиб по ГОСТ 6996-66. На завершающем этапе для проверки надежности выявленного условного критерия отбраковки было проконтролировано более 40 сварных швов, из которых АЭ-методом было отбраковано около $15 \%$. Механические испытания на статический изгиб полностью подтвердили результаты АЭ-контроля.

Что касается трубопроводов вообще и их подводных участков в частности, технология АЭконтроля включает в себя следующее. На берегах, в местах выхода трубопровода из воды, в шурфах на металлическую поверхность трубопровода устанавливают АЭ-преобразователи (по одному на каждом берегу). При ширине водного участка более 100 м АЭ-преобразователи необходимо также установить на локальных участках подводной части трубопровода из расчета один АЭ-преобразователь на 50..100 м длины трубопровода. АЭ-преобразователи надежно крепятся к металлической поверхности с помощью магнитных прижимов. Для хорошего акустического контакта поверхность трубы перед установкой на нее АЭ-преобразователя зачищают до металлического блеска. АЭ-преобразователи можно установить таким образом как для проведения разовых диагностических работ, так и для постоянного мониторинга состояния трубопровода в процессе его эксплуатации. В последнем случае места установки АЭпреобразователей вместе с самими АЭ-преобразователями покрывают изоляцией для предотвращения воздействия внешней среды на металлическую поверхность трубопровода. 
АЭ-преобразователи после их локальной установки на металлической поверхности трубопровода с помощью кабелей подсоединяются к АЭ-блоку регистрации и анализа АЭ-сигналов. Обработка поступающих АЭ-сигналов с выявлением критических параметров (числа АЭсобытий, их энергии, амплитуды, времен задержки и нарастания и т. п.) и месторасположения развивающихся дефектов осуществляется с помощью компьютера по специально разработанной программе. В основе технологии АЭ-контроля состояния трубопроводов лежит эффект Кайзера - развивающийся дефект проявляет себя на стадиях повышения или понижения давления при повторных нагружениях контролируемого участка трубопровода.

Разработанная нами система регистрации АЭ-сигналов построена по модульному принципу, где базовый АЭ-блок имеет восемь каналов регистрации. Вся система может быть размещена либо на стационарном посту регистрации, установленном на одном из берегов водоема, либо на передвижной лаборатории.

Реализация АЭ-контроля осуществлена на базе созданного нами универсального аппаратно-вычислительного комплекса, включающего в себя базовую восьми канальную АЭ-систему «Раскат» (Сертификат RU.E.27.004.A № 13171) и диагностические программные пакеты «Bartest», «Tubetest», «Weldtest» и «Anemon». При разработке АЭ-прибора мы исходили из того, чтобы он был прост, удобен и надежен в эксплуатации, имел небольшие размеры и вес, обладал высокой чувствительностью регистрации АЭ-сигналов, имел низкую себестоимость и удовлетворял основным требованиям, предъявляемым к приборам данного типа [5]. При этом максимально реализованы преимущества использования современной элементной базы. Внешний вид АЭ-системы «Раскат» показан на рис. 3.

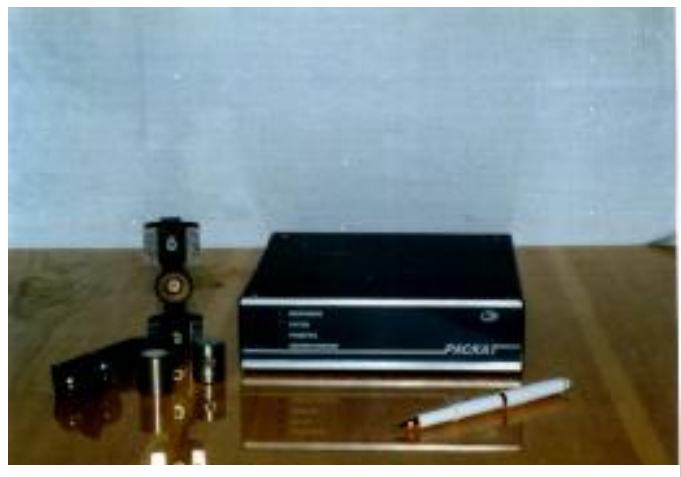

Р и с. 3. Внешний вид АЭ-системы «Раскат»

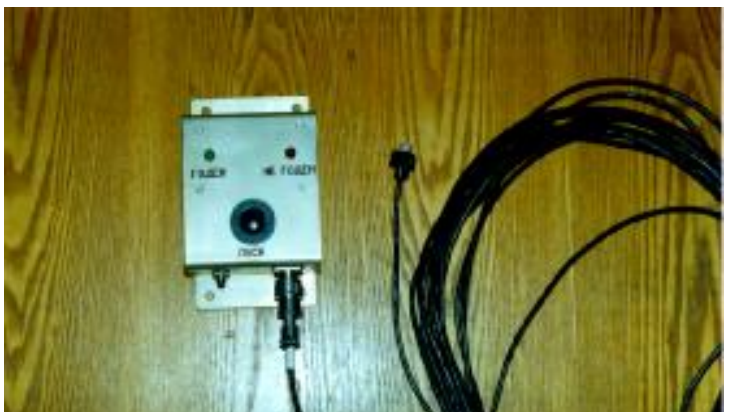

Р и с. 4. Внешний вид пульта управления АЭ-системы «Раскат».

На уровне программного обеспечения конечный результат АЭ-контроля адаптирован к требованиям реальных условий производства. При необходимости процесс АЭ-контроля сводится к простому нажатию кнопки «Пуск» на специальном пульте управления и регистрации результата контроля путем высвечивания одной из двух сигнальных ламп «Годен» или «Не годен», которые расположены на этом же пульте рядом с кнопкой «Пуск» (рис. 4). При этом мы исходили из того, чтобы АЭ-контроль мог проводить специалист со средним уровнем квалификации.

Заключение. Таким образом, на базе созданного аппаратно-вычислительного комплекса разработаны и практически реализованы АЭ-технологии контроля процессов вытяжки насосных штанг, гидроиспытания восстанавливаемых труб демонтированных трубопроводов, индукционной сварки плетей труб, а также контроля состояния труднодоступных подводных участков трубопроводов в процессе их эксплуатации.

\section{БИБЛИОГРАФИЧЕСКИЙ СПИСОК}

1. Грешников В. А., Дробот Ю. Б. Акустическая эмиссия. Применение для испытаний материалов и изделий. М.: Издательство стандартов, 1976. 272 с.

2. Артюхов В. И., Вакар К. Б., Макаров В. И., Овчинников Н. И., Перевезенщев В. Н., Ржевкин В. Р., Шемякин В. В., Яковлев $Г$. В. Акустическая эмиссия и ее применение для неразрушающего контроля в ядерной энергетике. М.: Атомиздат, $1980.216 \mathrm{c}$.

3. Иванов В. И., Белов В. М. Акустикоэмиссионный контроль сварки и сварных соединений. М.: Машиностроение, 1981. $184 \mathrm{c}$

4. Коллакот Р. Диагностика повреждений. М.: Мир, 1989. 497 с.

5. ПБ 03-595-03. Правила организации и проведения акустико-эмиссионного контроля сосудов, аппаратов, котлов и технических трубопроводов. М.: Госгортехнадзор России, 2003. 57 с.

6. Рыкалин Н. Н. Расчет тепловых процессов при сварке. М.: Машиностроение, 1951. 296 с

7. Лахтин Ю. М. Металловедение и термическая обработка металлов. М.: Металлургия, 1983. 360 с. 